\title{
3.2 UM PROJETO DE INFRAESTRUTURA VERDE PARA O MERCADÃO
}

\author{
A GREEN INFRASTRUCTURE PROJECT FOR THE \\ CENTRAL MARKET - MERCADÃO
}

Maria de Assunção Ribeiro Franco, Paulo Renato Mesquita Pellegrino

\section{MARIa de Assunção Ribeiro Franco}

Livre-docente em Arquitetura e Urbanismo pela Universidade de São Paulo, onde atualmente é Professora Titular. Coordena as atividades do Laboratório LABVERDE na FAU-USP desde 2007, onde é editora da REVISTA LABVERDE desde 2010. e-mail: mariafranco@usp.br

\section{Paulo Renato Mesquita Pellegrino}

Professor Associado junto ao Departamento de Projeto da Faculdade de Arquitetura e Urbanismo da Universidade de São Paulo, atuando na área da Arquitetura da Paisagem, na graduação e pósgraduação. É Vice-Coordenador do LABVERDE. e-mail: prmpelle@gmail.com 


\section{Um Projeto de Infraestrutura Verde para o Mercadão}

Em setembro de 2015 a Globo contactou três escolas de arquitetura: FAU USP, Escola da Cidade e FAU Mackenzie para participar do DESAFIO VERDEJANDO, uma das ações do Projeto Verdejando, dentro do Programa Globo Universidades. O projeto consistiu no acompanhamento televisivo do processo de projeto das 3 escolas, em uma série de reportagens especiais, sobre a questão do verde em São Paulo. Foi o terceiro ano que a série foi ao ar, nos telejornais locais de São Paulo, com a novidade da participação de equipes universitárias na discussão da questão da escassez do verde e seu impacto nas mudanças do clima urbano e apresentar propostas de possíveis intervenções, no combate aos efeitos desses fenômenos. O LABVERDE Laboratório Verde - foi indicado como representando a FAU USP em meio às outras 2 escolas. Assim, cada escola escolheu uma área em São Paulo como tema para estudo e proposições de cenários futuros.

\section{A área do Mercadão como o local escolhido pela equipe LABVERDE FAU USP.}

A área do Mercado Municipal de São Paulo, conhecido popularmente como Mercadão, se caracteriza pela intensa circulação de veículos e pedestres, trânsito de mercadorias e transporte de resíduos. Como resultado dessas intensas transações de serviços e comércio todos os espaços abertos em seu entorno foram ocupados por vias, calçadas, estacionamentos, que acabou por impermeabilizar completamente a superfície da área, com a total supressão de vegetação, incluindo as margens do Canal do Tamanduateí.

Esta região pode ser considerada o marco zero da ilha de calor de Cidade, sofrendo todos os efeitos de desconforto de temperatura, umidade, ventilação e qualidade do ar que esse fenômeno acarreta. Os usuários da área também são prejudicados pela ocupação preferencial dada aos veículos sobre pneus, tornando insegura a circulação de pedestres e o acesso ao Mercado. A isto se acrescenta a total aniquilação da paisagem original, incluindo o Rio Tamanduateí e suas margens, e a desqualificação, por usos não condizentes dos espaços abertos com o seu significado e valor, do patrimônio arquitetônico e urbanístico do Edifício do Mercado e de seu entorno.

O desafio foi visualizar uma paisagem verdejante, capaz de revitalizar e dar início à recuperação do local. Deste modo, foi realizada uma exploração das possibilidades de re- 
vegetar a área de modo a oferecer um maior conforto ambiental, segurança e facilidade de circulação e acesso. Dentro do conceito de Infraestrutura Verde, os cenários futuros acomodarão a infraestrutura de águas pluviais através de bio-retenção no projeto paisagístico, ao mesmo tempo que se abrem novas possibilidades de uso e apropriação dos espaços abertos que circundam o Mercado. O objetivo da re-introdução da vegetação, que possa se desenvolver vigorosamente, é oferecer a amenização das condições microclimáticas, fomentar o uso de pedestres e contribuir com um exemplo viável para a meta de produzirmos uma Cidade mais sustentável e resiliente às mudanças climáticas, a partir de um local emblemático e memorável da Cidade de São Paulo.

Como área de entorno do Mercado Municipal de São Paulo entende-se os espaços abertos públicos compreendidos entre a Rua da Cantareira, Rua Com. Assad Abdalla, Av. Mercúrio e Av. do Estado, com as margens do canal do Tamanduateí.

O trabalho consistiu de um Estudo preliminar de tratamento paisagístico em área de $38.795 \mathrm{~m}^{2}$, incluindo indicação de reafeiçoamento topográfico com esquema de drenagem naturalizada, definição de acessos, pisos, equipamentos, mobiliário, além da indicação, quantificação e locação das espécies vegetais.

\section{A Transformação: o Mercadão e seu entorno}

Originalmente situado na várzea do Rio Tamanduateí próximo a confluência do Ribeirão Anhangabaú, no sopé da colina do sítio da fundação da Cidade de São Paulo, o Edifício existente, projetado pelo Escritório do Arquiteto Ramos de Azevedo na década de 20 do século passado e inaugurado em 25 de janeiro de 1933, tornou-se um ícone do projeto de transformação da Cidade em uma grande metrópole. Reformado em 2004, o Edifício recuperou sua imponência, o que, ao mesmo tempo, ressaltou a degradação dos edifícios e dos espaços abertos do seu entorno. O que ocorreu como resultado de uma visão de política pública que privilegiou apenas o projeto isolado do edifício, ignorando o papel estratégico dos espaços livres e das redes de infraestrutura que o alimentam.

Desse modo, o mote que a equipe do LABVERDE FAU USP assumiu neste Projeto, foi rever essa lógica e imaginar novas possibilidades de ligações do edifício como um organismo vivo, em suas relações com os usos e ocupações do seu entorno. Para tanto, tomou-se como estratégia a configuração de uma trama verde e azul, que originada no próprio edifício, se propagasse desde seu entorno imediato até atingir os 
elementos mais estruturadores de sua base ecológica e sócio-econômica, procurando uma verdadeira sustentabilidade nas escalas urbanas mais amplas.

A própria orientação do edifício, alinhado aos pontos cardeais, inspirou as abordagens para a sua expansão virtual e articulações com a cidade em 4 frentes: Praça Norte; Praça Sul; Bulevar Cantareira e Bulevar Tamanduateí (Figura 1)

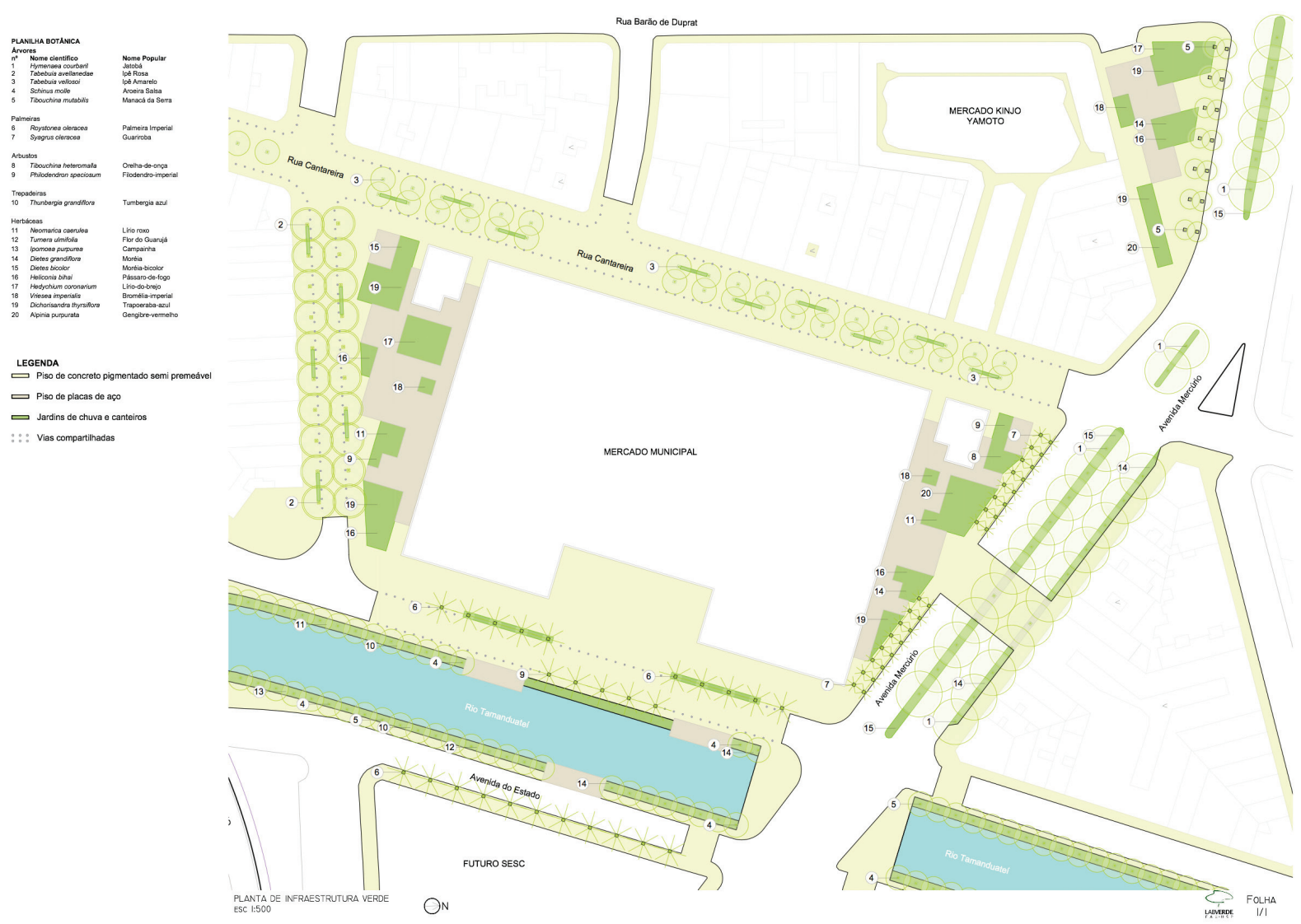

Figura 1 - Planta Geral do Mercadão e seu entorno próximo; Praça Norte, ladeada pela Av. Mercúrio; Praça Sul, ladeada pela rua Comendador Abdalla; Lado Oeste, Bulevar Cantareira e Lado Leste Bulevar Tamanduateí.

Os espaços livres do entorno são vistos como multifuncionais, acumulando as funções infraestruturais e de uso urbano, sobrepostas e simultâneas, podendo ser caracterizadas como:

Trama Azul: drenagem e tratamento das águas em bacias de retenção, pisos semiporosos e tubos enterrados encaminhando as águas para as galerias existentes e canais.

Trama Verde: definida pelo dossel arbóreo e jardins de chuva 
Trama Amarela: conexões e circulação de modo compartilhado de pedestres, bicicletas, transporte de mercadorias, transporte público e individual.

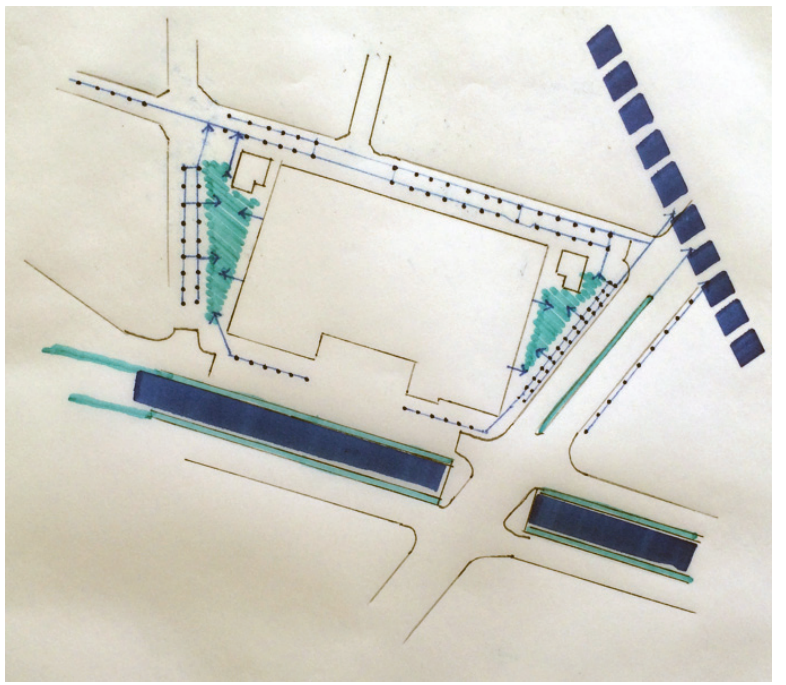

Figura 2 - Trama Azul: em azul claro as bacias de retenção, pontos e linhas azuis representam a coleta e encaminhamento das águas, faixa continua azul canal Tamanduateí e em faixa tracejada a galeria do Anhangabaú.

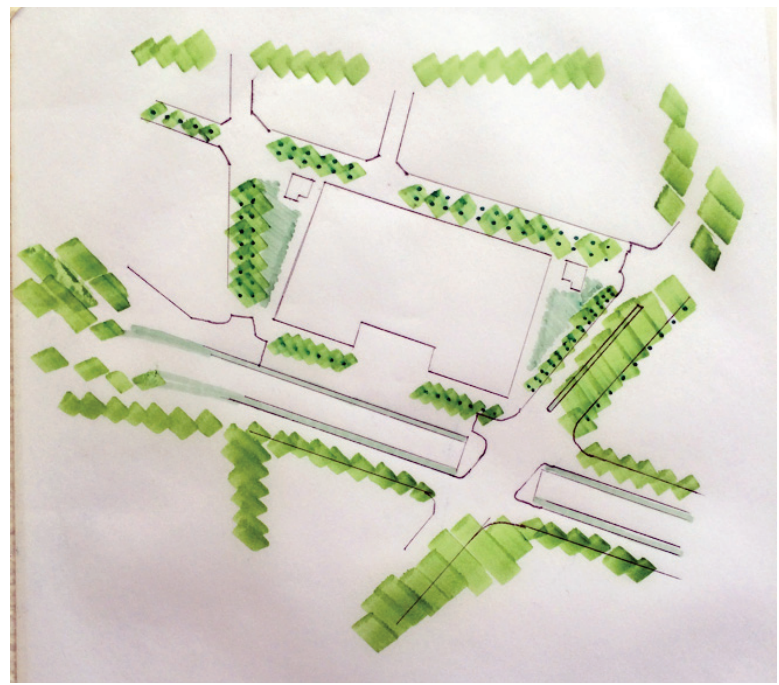

Figura 3 - Trama Verde: composta do dossel das árvores, suas caixas de plantio e jardins de chuva

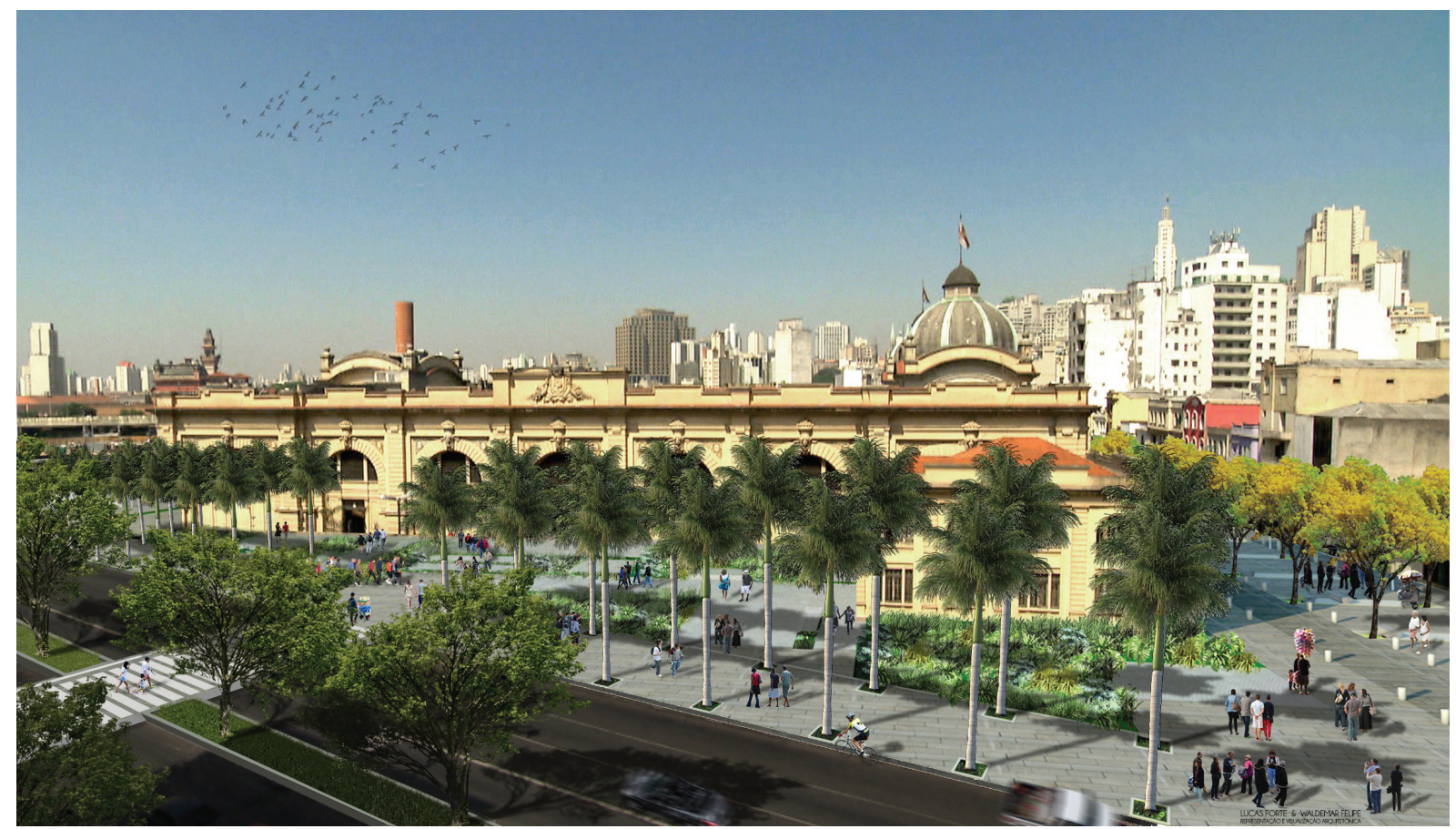

Figura 4 - Praça Norte 

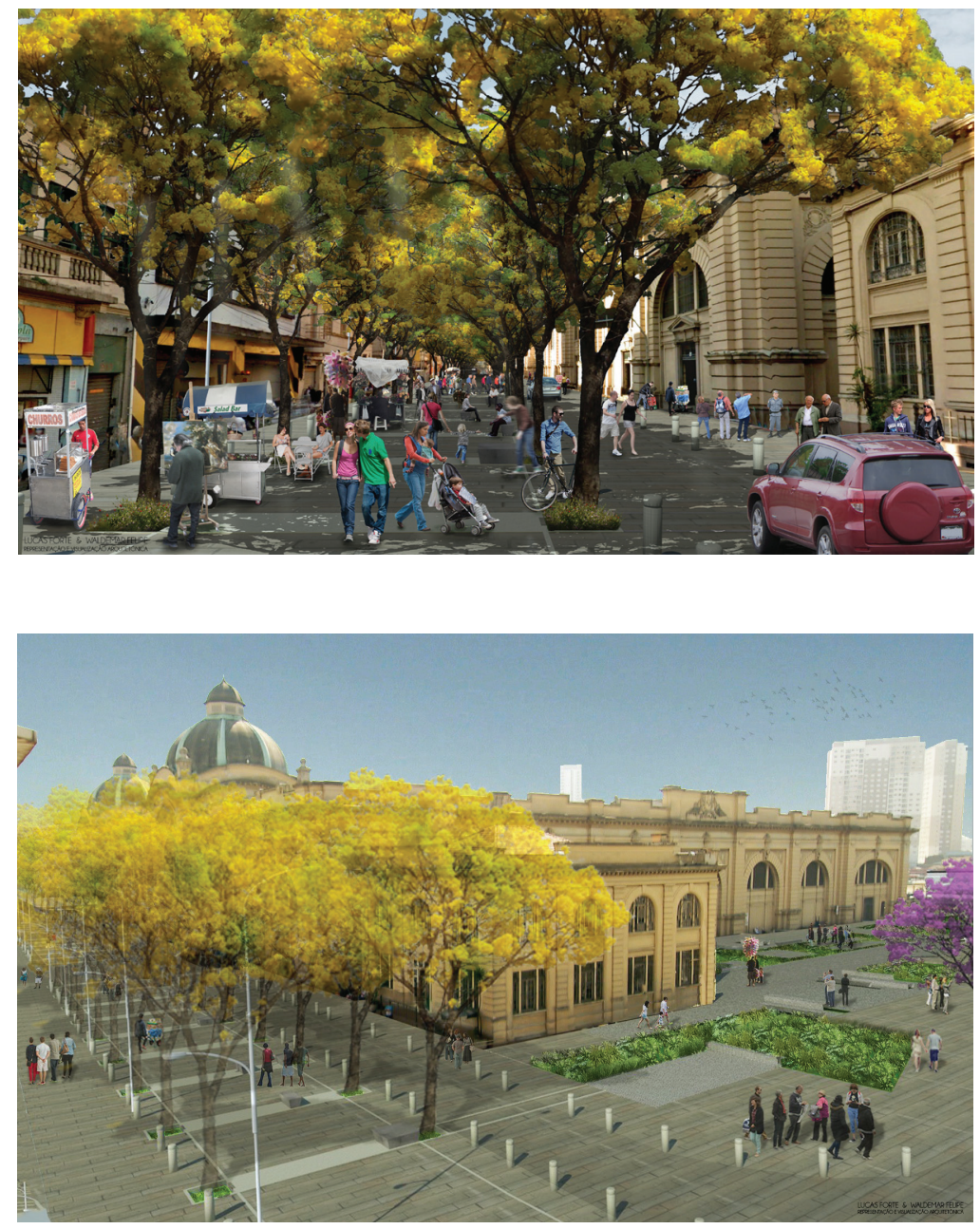

Figura 5 - Bulevar Cantareira

Figura 6 - Praça Sul

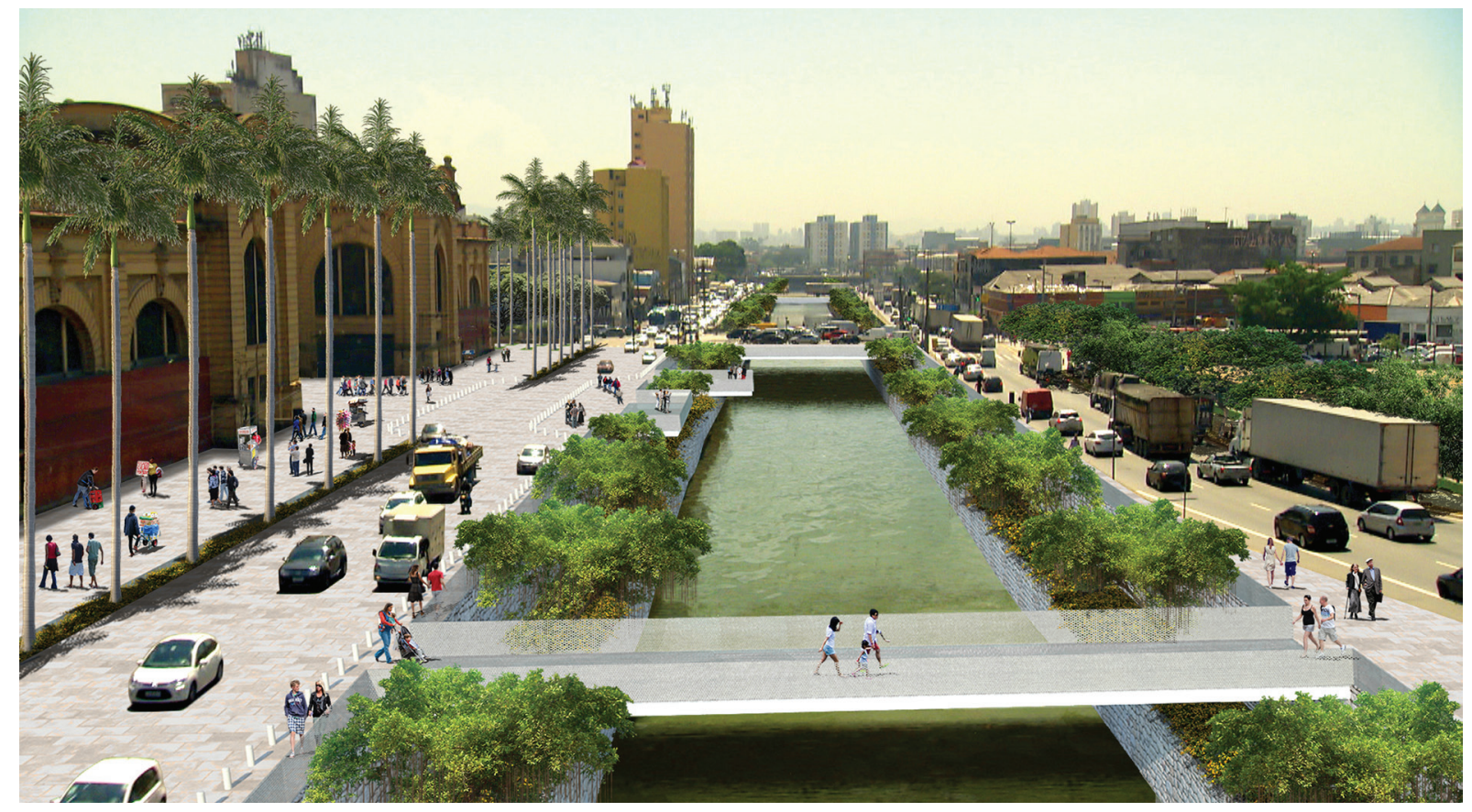

Figura 7 - Vista do Bulevar Tamanduateí 


\section{Cenários Futuros}

A fase descrita acima pode ser prevista para uma obra que possa ser realizada em um ano, após a elaboração do Projeto Completo de Infraestrutura Verde. Porém, o Projeto Mercadão pode transformar-se no stater de uma transformação urbana futura, que torne a Cidade de São Paulo mais amigável com o cidadão e com os processos naturais que se dão no local. Para isso não há como não considerar um desdobramento da fase inicial que una o Mercadão à outra margem do Tamanduateí, por meio de uma passarela de pedestres articulando as suas funções às futuras instalações do SESC e ao espaço do Parque Dom Pedro, devidamente recuperado.

Também pode ser imaginada um cenário futuro com a despoluição do Tamanduateí acompanhada da criação em margens recuperadas de um parque linear que vá das nascentes do rio, em Mauá, e chegue ao encontro de suas águas com o Rio Tietê, junto ao Anhembi. É possível prever uma última fase, em que as margens do Tamanduateí possam abrigar lagoas de contenção e praia fluvial, aos pés da colina do páteo do colégio, onde a cidade de São Paulo foi fundada e, por que não, ver pequenas embarcações deslizando em suas águas com a função de transporte de passageiros e lazer, como se pode apreciar em rios de cidades como Berlin e Londres. Porque não?

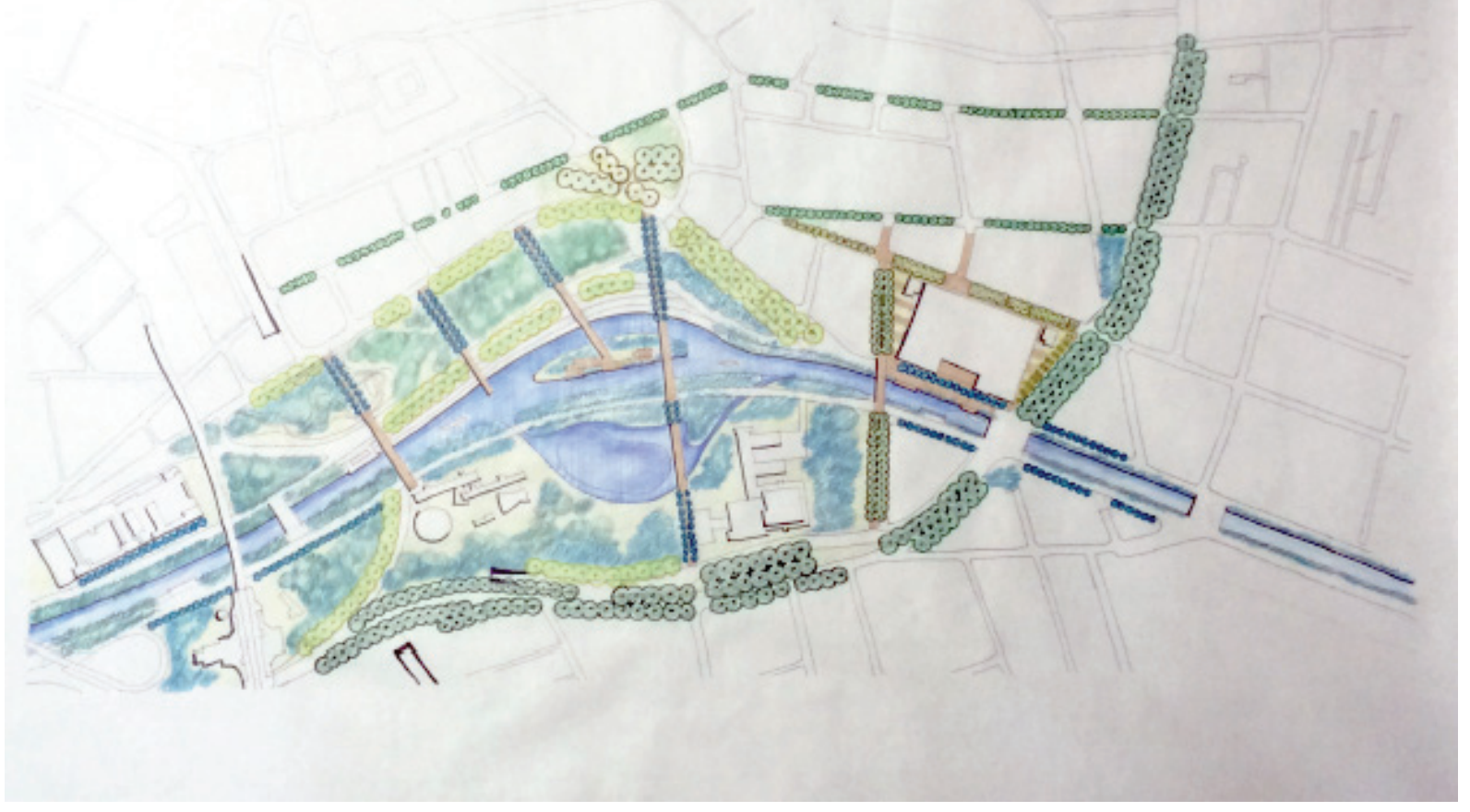

Figura 8 - Cenário Futuro 2050: Mercadão como parte do Parque do Tamanduate 